\title{
The Impact of Human Presence on the Behavioral Activity of Birds in Buea University Campus, Southwest Region, Cameroon
}

\author{
Melle Ekane Maurice $^{1 *}$, Nasako Noto Penda ${ }^{2}$, Ndzelen Salome Mendzen², Mbole Veronique ${ }^{2}$ \\ ${ }^{1}$ Department of Forestry and Wildlife Management, Faculty of Agriculture and Veterinary Medicine, University \\ of Buea, Southwest Region, Cameroon
}

*Corresponding Author: Melle Ekane Maurice, Department of Forestry and Wildlife Management, Faculty of Agriculture and Veterinary Medicine, University of Buea, Southwest Region, Cameroon

\begin{abstract}
The interaction of different elements within urban systems varies with the nature of land-use both temporally and permanently. Land-use dictates amount and type of land cover but the length of time a fragment is maintained within the surrounding dominant landscape, as well as its size strongly influences the composition and abundance of its flora and fauna. Urbanization modifies landscapes by changing resources such as food, water, perches, roosts, and nesting sites for birds. The main objective of this study was to examine the role of human presence on the social activity of birds in the campus of university of Buea. The research data was collected on check-sheets for a period of 2 months, 6 days a week, from 7:00am-6:00pm. The spot-count data collection method used witnessed 616 bird observations during the study. Simultaneously, data was collected on human activity state, day-period, bird species, bird location, and bird number. Bird location and humancampus activity showed a significant link, $\chi 2=8.696 \mathrm{~d} f=4 P<0.05$. Moreso, bird activity showed a significance on human activity, $\chi 2=10.600 \mathrm{df}=8 \mathrm{P}<0.05$. Similarly, bird number associated significantly with human activity in the campus, $\chi 2=19.842 d f=20 P<0.05$. Additionally, bird location associated significantly with their activity, $\chi^{2}=121.799 d f=8 P=0.000$. Besides, bird activity related significantly with the day-period, $\chi^{2}$ $=11.061 \mathrm{~d} f=8 \mathrm{P}<0.05$. Also, bird activity showed a link with the day-period, $\chi 2=11.061 \mathrm{~d} f=8 P<0.05$. The day-period revealed a significant link with bird number, $\chi 2=22.822 d f=20, P<0.05$. This survey showed the village weaver bird (Ploceus cucullatus) (17.86\%) as the most dominant bird species in the campus of university of Buea. However, the survey also recorded an observation of $11.36 \%, 9.09 \%, 7.79 \%, 7.63 \%, 7.30 \%$, and $6.01 \%$ on little weaver bird (Ploceus luteolus), grey-headed sparrow (Passer griseus), pied crow (Corvus albus), orange-cheeked waxbill (Estrilda melpoda), and little weaver bird (Ploceus luteolus), respectively. The study discovered that the university campus of Buea does not serve as a conflict zone for humans and birds, rather the social activity of birds was observed consistent with low human population presence.
\end{abstract}

Keywords: Urban systems, Landscape, Human activity, Bird activity, Bird species.

\section{INTRODUCTION}

Historically urban areas have been less considered as biological environments but more recently it has been appreciated that they are part of a continuum at one end of a gradient, ranging from natural wildlands to rural, suburban and urban centers (Blair 2001). Intensely, urban environments are uniform throughout the world (Clergeau et al. 2006); they are relatively simple with less complicated food webs, strong abiotic influences and imported food subsidies (Rebele 1994). The dominant features of cities include, majority of their land surface permanently covered by pavements or buildings - above $80 \%$ at the urban core (Blair \& Launer 1997), increased amounts of energy they use and create, amplified productivity they make available because of their altered state, and wide variety of environmental conditions they exhibit (Rebele 1994). Because most cities exist in a state of permanent flux, the altered environment does not have enough time to equilibrate through succession before being modified again (Rebele 1994). This makes the accepted theories of stability and equilibrium inadequate for interpreting these systems (Rebele 1994). It might therefore be debated that ecological 'rules' such as those driving diversity, density, dispersal, and distribution in urban areas are different from those of more natural landscapes. The impact of human activities on the environment has been major. There are no ecosystems on earth's surface still free of pervasive human influence (Vitousek et al.1997). The growth of cities and the process of urbanization worldwide has been a predominant cause of species extinction. This pattern is likely to continue, more so in developing countries where human impact on ecosystems will be further 
exacerbated due to the faster pace of urban growth (Marzluff \& Kern 2001), with local governments having first to meet the basic needs of the much increased urban populations within cities that have limited infrastructure.

Cities consist of mixture of built habitats and green patches. Only a few species can exist and thrive in the most built part of the city where vegetation is almost absent such as business districts and industrial zones. Thus, urbanization increases abundance of feral pigeons, swallows, swifts and few other species that breed there. If urbanization induces stress, one should expect to find differences in stress hormone levels and blood parasites between urban and wild-land bird. In Germany, urban blackbirds (Turdus merula) showed lower levels of corticosterone stress levels than forest birds. This may suggest that individuals that modify their stress response can adapt to presence of humans than rural birds such as black billed magpie (Pica pica) (Hilden 1965). Birds constitute an important component of agro-ecosystems and the role of birds in agro-ecosystems is gaining more attention. As depredators of insects, birds stand supreme among vertebrates. In developing countries like India, agro-ecosystem is not completely modernized (Clergeau et al 1998). The use of pesticides to control insect pests is avoided in certain areas, especially for low revenue crops like millet, maize etc. In such situations birds become important predators such as insectivorous birds needed in the agroecosystem by use of appropriate management practices (Saini et al 1994).

Agriculture provides a concentrated and highly predictable source of food for birds. This food in general is of three kinds (i) grain, seeds and fruits, (ii) green vegetation of the crop plants and grasses, (iii) insects, other arthropods, rodents etc found in soil, crops and other plants (Schifferli 2001). Studying birds can help researchers discover how human interaction affects communities and ecosystems, as a result can create better solution for conservation. Urbanization and agriculture both have impacts upon natural landscapes. However urbanization generally has more permanent and damaging effect than agriculture (McKinkey 2002). As a result, recent conservation efforts have been more geared towards the ecological effects of urbanization. However, little research has focused on native grassland areas and the proximity of those areas to urban settings (Chamberlain et al 2009). In particular, we lack information on whether or not remaining tall grass fragments continue to function as valuable refuges when they become increasingly surrounded by urban development. Fragmentation from agriculture and urbanization also reduces the size of habitat patches and isolates them from each other, which could affect the species found in the remaining fragments (Johnson 2000). Herkert (1994) concluded that grassland birds of conservation concern tend to avoid smaller patches of grassland and found that the number of breeding birds were greater in larger patches of prairie. The amount of edge area within a prairie also affects bird communities, and the size and shape of a patch correlates with the amount of edge area (Hmaer etal 2006).

Due to the co-occurrence of high species diversity and intensive human impact in cities species conservation should not only concentrate on natural areas but also on urban areas (Cincotta 2003). Classical instruments of species conservation are nature reserves, which can be found in both cities and countryside. However, protected habitats in cities are generally not typical urban habitats, but semi-natural habitats within an urban landscape. Since protected areas are not isolated from the surrounding landscape matrix, reserves in urban and rural regions are exposed to different environmental conditions. Although they are at a different scale than cities, protected areas within a city are influenced by the urban climate, e.g. the heat island effect and air pollution (Landsberg 1981).

Urban planners need better information about the factors affecting the distribution of species and structure of communities in order to create or maintain biodiversity in urban areas. Conservation or restoration efforts related to urban wildlife focus on limiting artificial habitat, developing citizen participation in wildlife conservation, improving the quality of life of urban dwellers, and educating them about ecological concepts (Gilbert 1989). The interest of urban residents for their immediate environment is becoming increasingly important. Therefore, urban wildlife diversity can significantly influence the management of biodiversity at regional, national and even global scales (Hadidian et al. 1997). In general, human activities have produced similar ecological structures in urban areas even in different bio-geographical regions. The response of birds to these environmental changes could lead to the dominance of bird communities by a few very abundant species (Bezzel 1985). This, in turn, might lead to the general hypothesis that urbanization causes uniform bird communities in urban areas (Jokimäki 1996). 


\section{Materials ANd Methods}

\subsection{Description of the Study Area}

Buea municipality is situated between longitude $9^{0} 16^{\prime} \mathrm{E}$ and latitude $4^{0} 9^{\prime} \mathrm{N}$ (fig. 1) (Tanjong 2014; Fitton et al 1983). The municipality is bounded to the north by tropical forest on the slope of mount Cameroon (4100m above sea level). The population is estimated at about 300,000 people of whom two-thirds live in the city of $\mathrm{Buea}$, while the rest in villages. The settlement pattern forms a closed ring around the foot of the mountain with no permanent settlements on altitudes above $1500 \mathrm{~m}$. The indigenous people in the area are Bakweri, Bomboko, Balondo and Bakolle (Ekane, 2000). With an equatorial climate, temperature is moderate with a slight seasonal variation (rainy and dry season) (Tanjong 2014). The region is also very diverse in fauna with over 370 species of wildlife recorded. The sub-montane and montane habitats are part of Cameroon mountain endemic bird area. So far, 210 species of birds have been recorded, out of which 8 are threatened and 2 strictly endemic mount cameroon francolin (Francolinus camerunensis) and mount cameroon speirops (Speirops melanocephalus) Ekane (2000). Agriculture is the most important source of livelihood in the area accounting for about $80 \%$ of household income in most villages. Other sources of income include hunting, timber and non timber forest products (NTFP) exploitation, petty trading, and cattle rearing (Tanjong 2014).

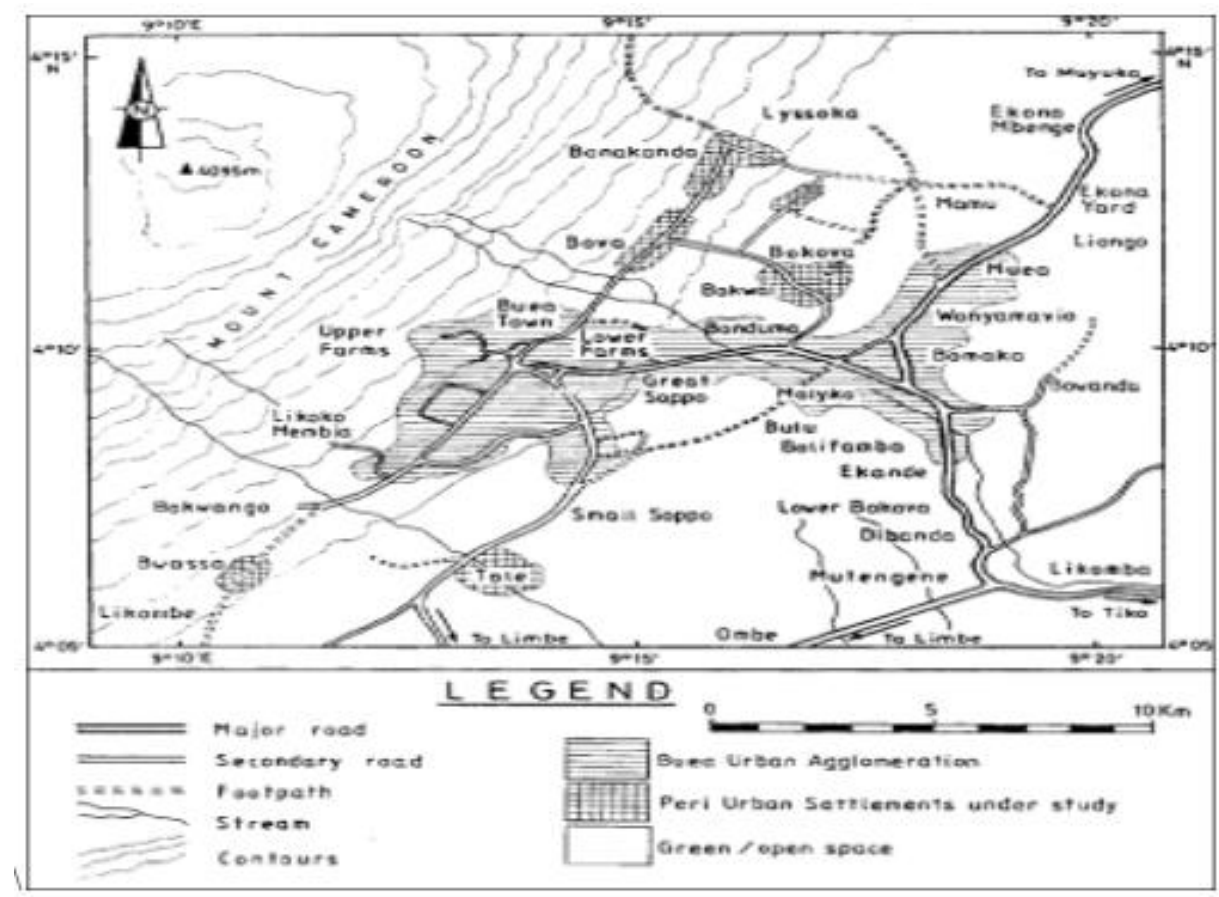

Figure1. Map of Buea Municipality

\subsection{Data Collection Method}

The research data collection program was done by a research team made up of four persons, the principal investigator and three other student colleagues. The two-month study was carried out in the campus of university of Buea. The research data was collected between 7:00am - 6:00pm each day of the study, and was done 6 days each week, Monday - Saturday. The team visited all the locations of the university campus on a daily bases to record observations on bird species, their activity, locations, day-period, and human activity. A five-minute-spot-count method was used throughout the data collection period. Point counts (where the observer is sedentary at one place), is among the most frequently used techniques for monitoring terrestrial birds (Rosenstock et al. 2002). Bird population monitoring programs vary in how they are conducted. The Breeding Bird Survey (BBS), for example, is run in Britain and variants of it are used by 18 other European countries (Spurr 2005). Five-minute point-based distance counts are used in France that specify the area of the sampling site and the distance bands used around each point, ( $<25 \mathrm{~m}, 25-100-\mathrm{m}$, and $>100-\mathrm{m}$ ) (Spurr 2005). In the United States the BBS uses three-minute counts of all birds seen and heard within a $400 \mathrm{~m}$ radius around the point. The BBS programs monitor the trends in terrestrial bird populations and all results are published on-line (British Trust for Ornithology 2008). 
Still other research (Bolger et al 1997; Melles et al. 2003) used point counts to monitor either the abundance of breeding birds or to assess urban bird biodiversity in urbanizing landscapes. In New Zealand the five-minute bird count (FMBC) was adopted as the standard method of avian community monitoring, particularly in forests (Dawson \& Bull 1975). It has persisted as the most widely used means of determining the status and trend of bird populations within forested populations (Hartley \& Greene 2008). The FMBC is an index measure only because it detects just a proportion of all birds present while some remain hidden in surrounding vegetation (Hartley \& Greene 2008). It is attractive because it is cheap and requires minimal effort while still allowing large numbers of controlled counts to be conducted. The method is suited for use in densely vegetated habitat, because the observer is standing still, for detecting birds that are more inconspicuous or cryptic (Hartley \& Greene 2008).

\subsection{Data Analysis}

The research data collected on check-sheets was analyzed by the use of SPSS version 20. And the main statistical model used was chi-square to test the relationships existing between the variables such as bird species, bird activity, bird number, human activity, day-period and the bird location. Exploratory analysis was used to further examine the frequency of variables like human activity, bird location, and day-period.

\section{Results}

This survey showed village weaver bird (Ploceus cucullatus) (17.86\%) as the most dominant bird species in the campus of university of Buea. However, the survey also recorded an observation of $11.36 \%, 9.09 \%, 7.79 \%, 7.63 \%, 7.30 \%$, and $6.01 \%$ on little weaver bird (Ploceus luteolus), grey-headed sparrow (Passer griseus), pied crow (Corvus albus), orange-cheeked waxbill (Estrilda melpoda), and little weaver bird (Ploceus luteolus), respectively (fig. 2). The least observed birds were common bulbul (Pycnonotus barbatus) (6.01\%), black-crowned waxbill (Estrilda nonnula) (5.84\%), blue-breasted kingfisher (Halcyon malimbica) (4.87\%), woodchat shrike (Lanius senator) (4.54\%), lavender waxbill (Estrilda caerulescens) (3.41\%), and cattle egret (Bubulcus ibis) (2.92\%) respecitively.

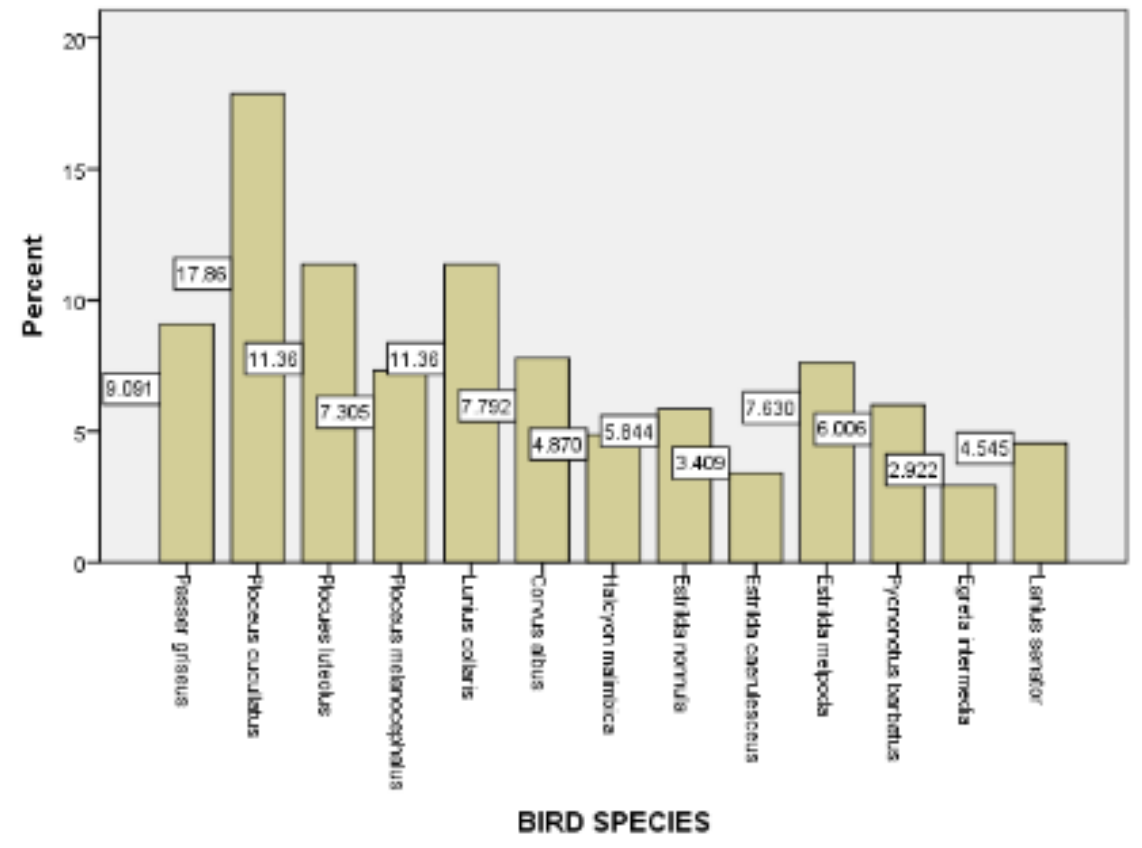

Figure2. Bird species

Bird location and human-campus activity showed a significant link, $\chi^{2}=8.696 \mathrm{df}=4 \mathrm{P}<0.05$ (fig. 3). Birds were observed in all the locations; however, their presence was more observed during the low human-campus activity. High human activity in the campus generates a noisy environment for the birds, for this reason many birds are believed to be scared some of these locations during this period. Also, the high human-campus activity periods contributed to scare birds, consequently their number was reduced in the campus. Most of the birds were observed flying out the campus area, unlike during the low human-campus activity periods when the birds did not show a similar behavior. This study also 
made a surprising discovering on the strange reduction of bird activity during the absence of human campus-activity. However, the expectation that the absence of human-campus activity would increase bird population was strangely not met by this study. Birds' attraction to low human-campus activity might rather be an adaption derived from a low human population, creating a noiseless environmental condition that could be tolerated by the bird population.

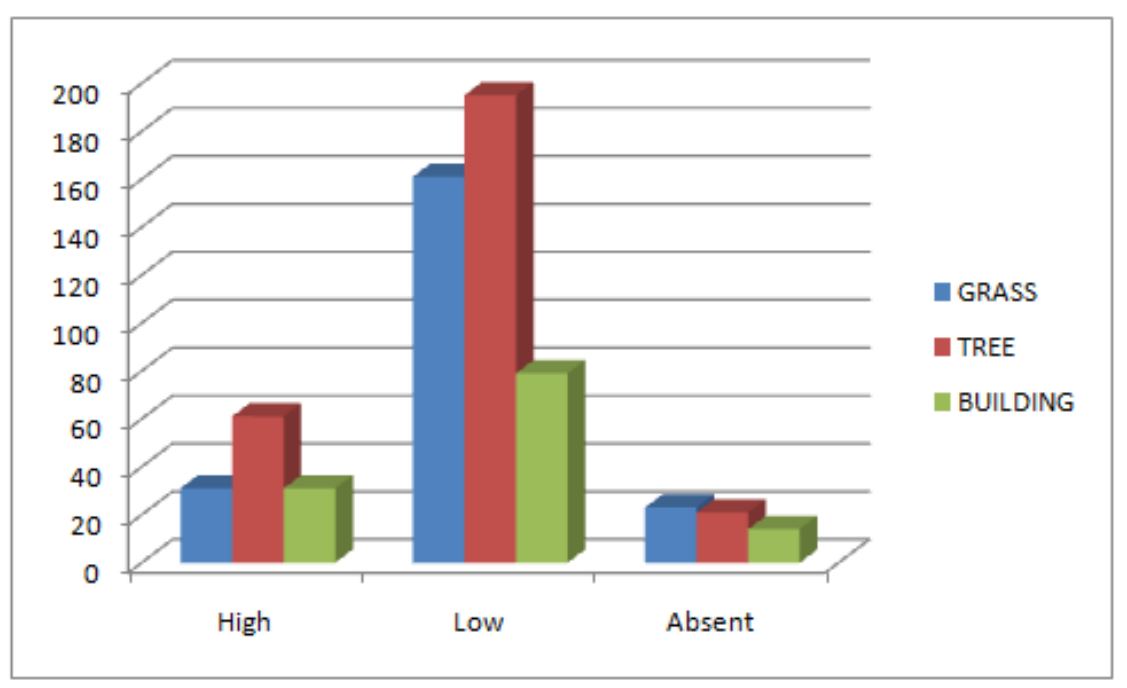

Figure3. Bird location and human activity

Moreso, bird activity showed a significance on human activity, $\chi^{2}=10.600 \mathrm{df}=8 \mathrm{P}<0.05$ (fig.4). This study revealed that the presence of human population in the campus did not alter bird activity; however, low human activity rather increased bird activity(70.62\%), while both the absent and high human activity decreased their activity (9.42\%), and (19.97\%) respectively (fig. 5).

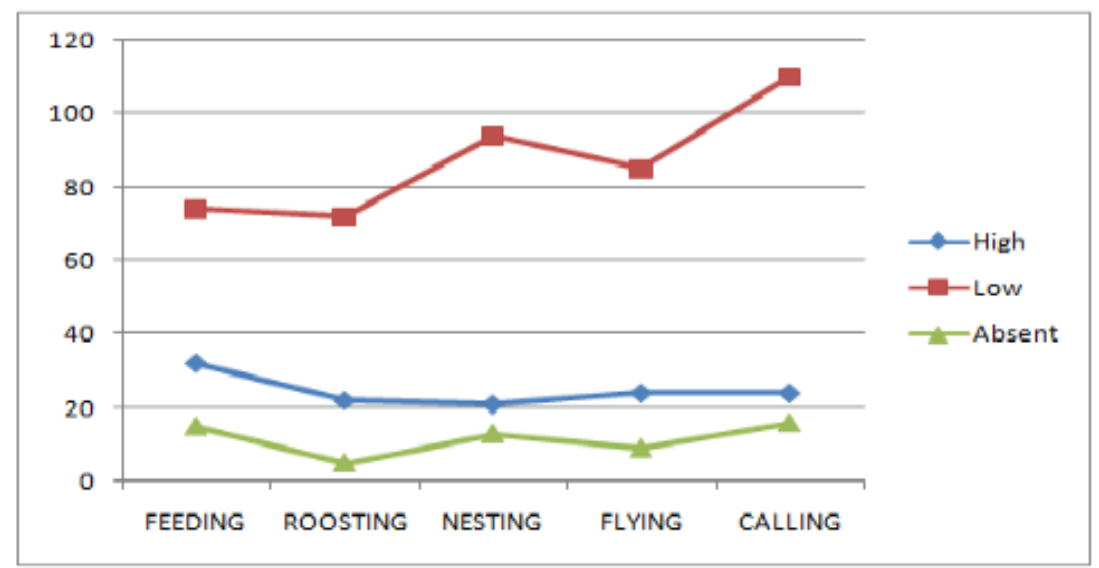

Figure4. Bird activity and human activity

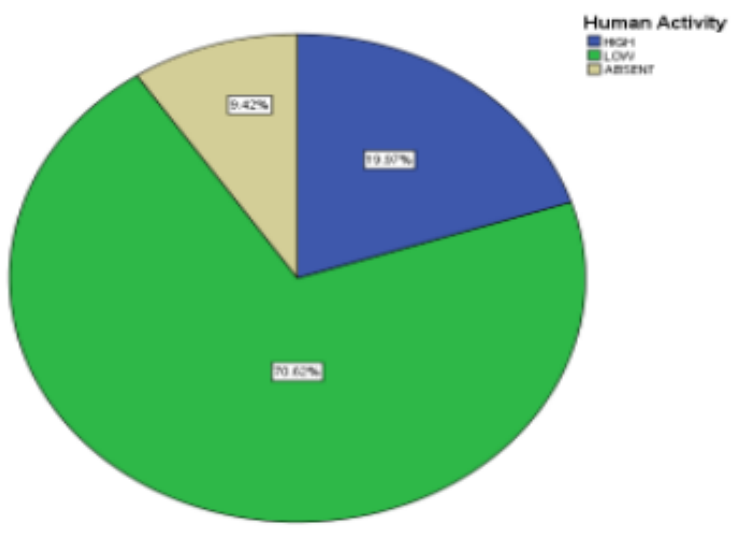

Figure5. Human population and bird activity 
The bird number also associated significantly with human activity in the campus, $\chi^{2}=19.842 \mathrm{df}=20$ $\mathrm{P}<0.05$ (fig. 6). The birds in the study area are believed to have acquired adaptation in co-habiting with a low human population; however, a low human population witnessed a high activity profile of the birds. Most wildlife species manifest a significant shy behavior in the presence of human population, but when they observe this harmless human presence for a long time, they develop an adaptive behavior known as habituation. Wildlife habituation is a behavior acquired by wildlife to withstand human presence at close proximity over a long period of human imposition.

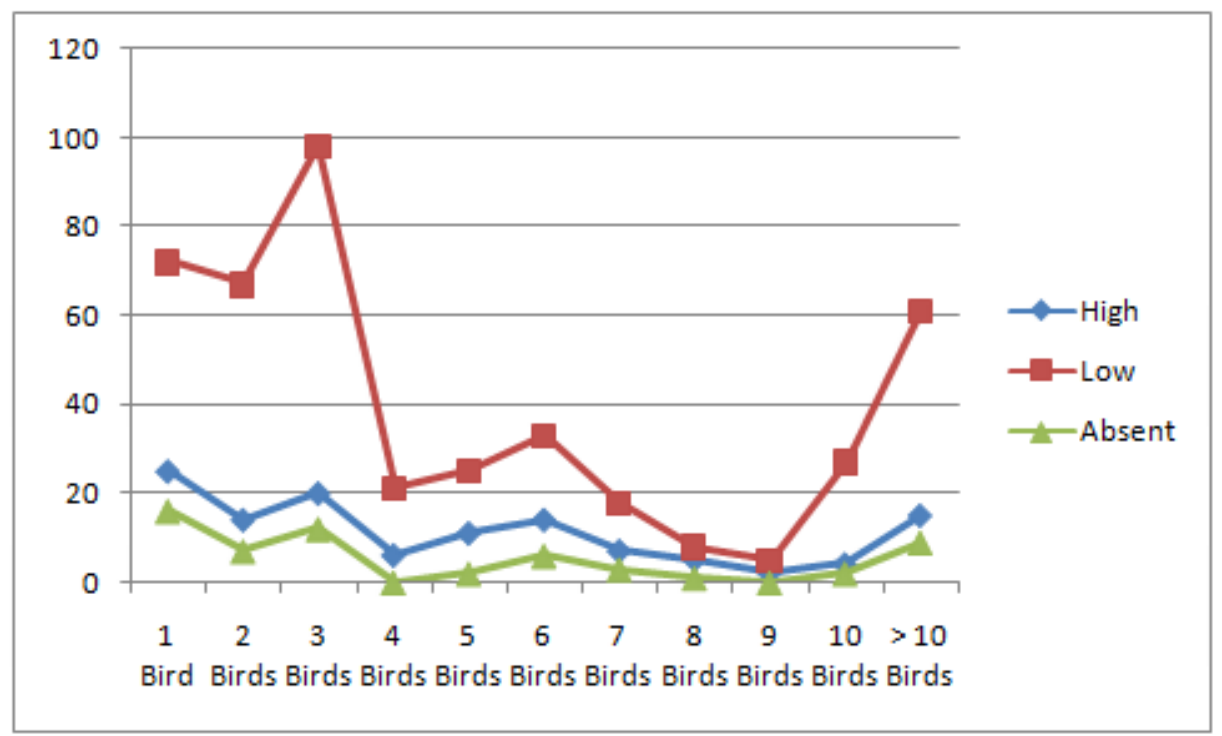

Figure6. Bird number and human activity

Additionally, bird location associated significantly with activity, $\chi^{2}=121.799 \mathrm{df}=8 \mathrm{P}=0.000$ (fig.7). Generally, an activity of wildlife can be determined by its geographical location in aquatic and terrestrial environments. The availability of food resources and security are believed to be among the favorable condition needed by wildlife such as birds to niche. In this study, three bird locations were taken into consideration, grass vegetation, tree vegetation, and the buildings. These areas recorded activity rate of $34.90 \%, 44.97 \%$, and $20.13 \%$ on grass vegetation, tree vegetation, and buildings respectively (fig. 8). The university campus of Buea is beautified with a tree-vegetation cover used by birds for social activities, acacia trees (Acacia spp), avocado (Persea americana), palm (Elaeis spp), plums (Prunus domestica), and guavas (Psidium guajava) are among the dominant trees found in the campus. The ecological role played by these trees has contributed to the bird activity increase in the campus, nonetheless, nesting and feeding were the most prominent activities anchored by these trees.

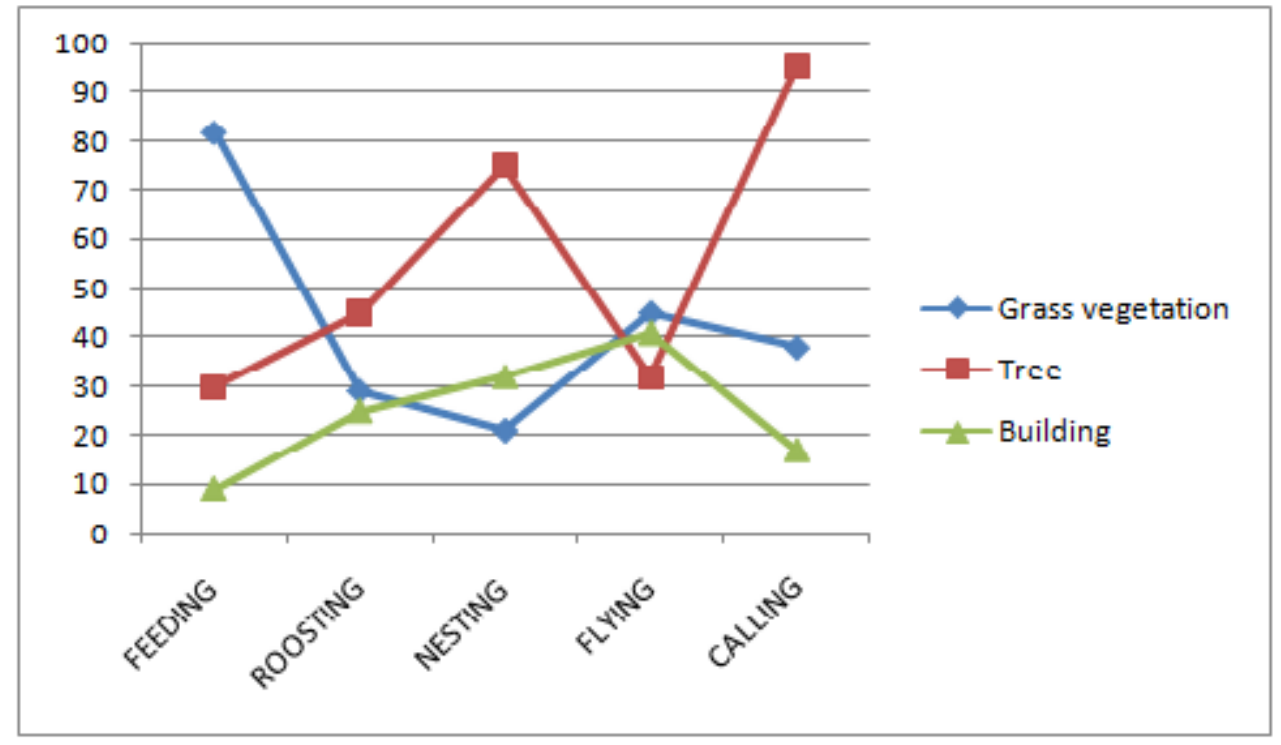

Figure7. Bird activity and location 


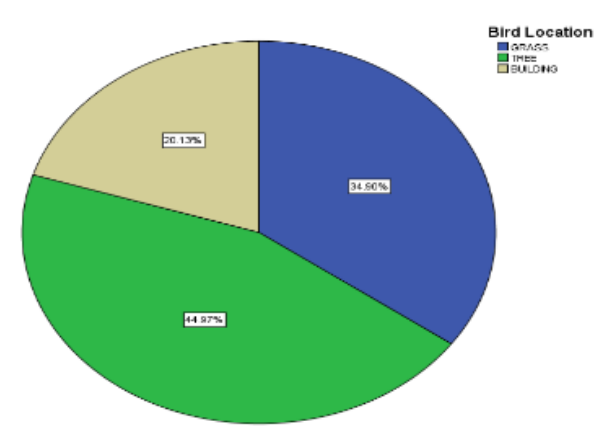

Figure8. Bird location

Bird activity related significantly with the day-period, $\chi^{2}=11.061 \mathrm{df}=8 \mathrm{P}<0.05$ (fig.9). Throughout the day, birds were observed active, however, both the morning and afternoon periods witnessed a high activity levels than the evening periods. The activity pattern of most wildlife species experience a gradual increase from morning to mid-day then slows down. However, the mid-day period is believed to take more rest-time in wildlife, and then towards the evening period there was increase in activity such as feeding for the night.

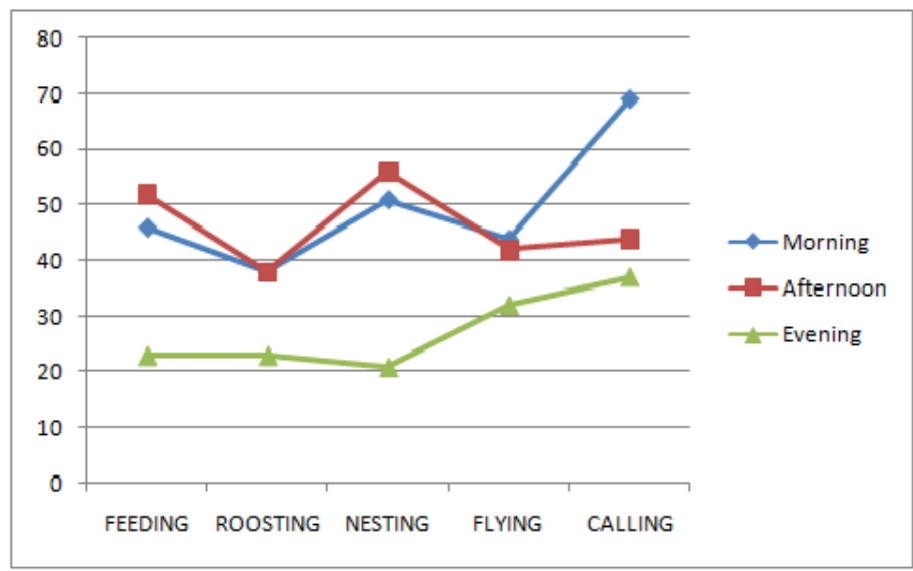

Figure9. Bird activity and day-period

The day-period revealed a significant link with bird number, $\chi^{2}=22.822 \mathrm{df}=20, \mathrm{P}<0.05$ (fig. 10). Different periods of the day were observed with different activity levels; however, the bird population activity involvement was throughout the day-period, but these activities were not uniformly spread. The morning, afternoon, and evening periods of the day recorded $40.26 \%, 37.66 \%$, and $22.08 \%$ respectively (fig. 11). The study witnessed the highest bird activity in the morning period of the day. A gradual increase in bird population witnessed a significant increase in activity. Wildlife behavioral activity study has been much associated with the morning period of the day. The morning period, however, is characterized with sun-set with a moderate temperature especially in the dry season; this period favors the terrestrial activities of most species of wildlife such as birds in flight, feeding, roosting, nesting, and vocalization.

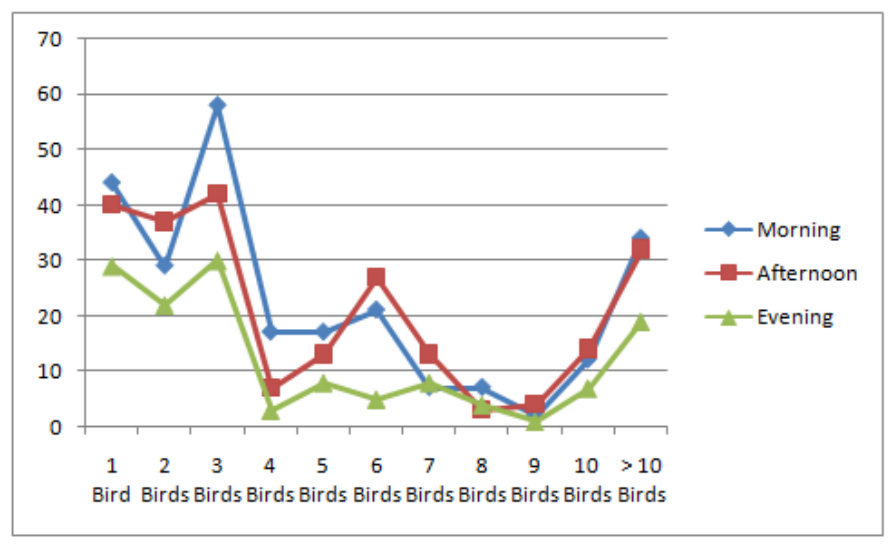

Figure10. Bird number and day-period 


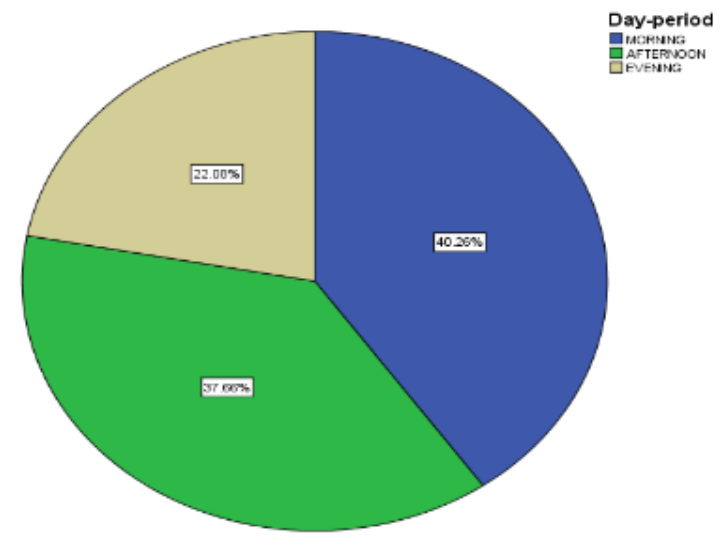

Figure11. Day-period

\section{DISCUSSION}

The urban ecosystem is characterized by elevated levels of noise which can interfere with local communication. Birds use vocalizations to warn danger, defend a territory and attract mates (Warren et al 2006). The most prominent noise source in urban ecosystems is traffic and consequently the majority of urban acoustic studies concentrate around roads. The noise within urban ecosystems is at low frequencies, usually below $2000 \mathrm{~Hz}$. Therefore, birds with higher frequencies or those with the ability to shift their frequencies will have advantage to communicate amid the urban noise. A recent study showed that house finches (Carpodacus mexicanus) adjusted their songs in response to noisy areas within a city by raising the low frequency of their songs and decreasing the number of notes per song (Edgar et al 1994). Bird species in urban habitat enjoy higher resource abundances than species in wild-lands and rural areas because of more food abundance. This allows birds to extend their breeding season by developing their gonads 3 weeks before forest individuals due to increase in food subsides (Fernandez 2000). Urban birds are expected to produce lower quality off-springs than rural birds. One reason for this is that selection may favor parents producing large broods at the expense of fledgling's body condition because even low-quality offspring may have high chances of survival in urban habitats (Richner 1989). Several studies found that nestlings in urban habitat fed by reduced amount of low quality food reached lower body mass than nestlings in rural habitats. This is because of the contamination of food, water or soil by toxic materials that have detrimental effect on the nestling development (Janssens et al 2003).

The interaction of different elements within urban systems varies with the nature of land-use both temporally and permanently. Land-use dictates amount and type of land cover but the length of time a fragment is maintained within the surrounding dominant landscape, as well as its size strongly influences the composition and abundance of its flora and fauna. Urbanization modifies landscapes by changing resources such as food, water, perches, roosts, and nesting sites (Emlen 1974; Mills et al. 1989). Moderate development increases ornamental vegetation water supply, primary productivity and the area of edges (Blair 1996). The degree to which birds can exploit these novel environments will determine peak densities and richness in any given area. Earlier research findings describe three general effects of increasing urbanization on avian fauna (Blair 1996): (1) species composition change, (2) species numbers decrease and (3) species abundance increase. These patterns in fact reflect the depth of disturbance that parallels urban development. In an attempt to further clarify these patterns Blair (1996), studying land-use and avian diversity along an urban gradient, found a divergence from these patterns. He showed that Shannon diversity (Shannon \& Weaver 1963), species number, bird density, and bird biomass all peaked at intermediate levels of urbanization rather than at less modified sites when considering bird biomass at most urban site (Blair 1996). This is called the intermediate disturbance hypothesis and in cities, modified green spaces may represent this intermediate disturbance between unmodified habitat and the highly modified urban habitat.

The flora of urban landscapes can be substantial and diverse but exists mostly as remnant fragments in the case of native vegetation, or as cultivated gardens or plots in suburbs and city parks (McKinney 2006). Increasingly planted traffic islands and wooded urban and sub-urban streets provide intermediate habitat. In the building of new cities, establishment of exotic species occurs in proportion to the degree 
of disturbance, with alien plants only colonizing up to the border of the altered zone (Rapoport 1993). Invaders and weeds prosper where water is supplemented and weedy species are dispersed by wind, and cultivars by humans. Birds disperse the seeds of invasive shrubs and fruit, with some plants largely depending on birds for dispersal. Conservation and management of urbanized and urbanizing areas for the purpose of increasing bird biodiversity is complex. It requires understanding of the causative processes in diversity patterning (MacArthur 1972), and of how diversity arises and is maintained in space (Lande 1988).

According to random sampling hypothesis, urban environments should have higher species diversity because cities attract more individuals from the regional species pool (Connor and McCoy 1979). The urban bird community is most strongly influenced by vegetation with the volume of native vegetation being most closely correlated with native bird density and species richness (Mills 1999). The urban environment favors species that can utilize small, discontinuous patches of vegetation and densities of urban exploiters are strongly correlated with lawn area and the volume of exotic vegetation. The relationship between habitat variables such as vegetation density and species diversity has traditionally been explained in terms of food abundance and foraging niche space. The role of species interactions in urban bird populations and in urban bird population dynamics and community structure may suggest that solutions for the loss of diversity cannot be based on habitat alteration. Creating a proper habitat for a given species may not be sufficient to attract it into the city if it suffers from aggressive interactions from local urban species or human disturbances (Whittaker and Marzluff 2012).

Birds are the key species in an agricultural ecosystem for maintaining the ecological balance (Haslem and Bennet 2008). In many developing countries like India, agro-ecosystem is not completely modernized. The use of pesticides to control insect pests is avoided in certain areas, especially for low revenue crops like millet maize etc. In such cases birds become important bio-control agents suppressing the insect pests (Parasharya 1994). Research on the role of birds in the control of insect pests of agricultural areas is on top priority in India (Dhindsa and Saini 1994). Wetlands associated with agricultural lands also attract more number of bird species, especially migratory species. Birds are integrated with farmers in everyday activity, since it is an important and effective organism, controlling pests in the agricultural lands (Blus and Henny 2002).

An increase in complexity of vegetation structure, floristic composition and heterogeneity can increase niche diversity of birds and vice versa. Both natural and human induced disturbances such as floods, drought, deforestation change in land-use, natural resources and seasonal climatic changes affect vegetation and bird community structures (Chinchilla 2009). Previous research on the effects of urbanization on bird communities focused on birds that rely on woodlands and shrub-lands. Some of these studies have found that species richness of birds decreases with increase in urbanization (Germaine et al 1998), while other studies have found that species richness and diversity increase at moderate levels of urbanization, decreasing with high levels of development (Blair 2004).

\section{CONCLUSION}

The best description of human-wildlife relationship is conflict; the historical human dependence on wildlife has been based on consumption, pets, tourism, and research. The bio-medical research on wildlife such as primates has opened great doors to the invention of medications used for human health care services. Nonetheless, the quest for more understanding on the ecology of wildlife species such as birds has revealed a significant human benefit on areas like environmental indication. Additionally, the beautiful body morphology of some species of birds has created another attraction need for birds to be conserved. The campus of university of Buea harbors about 13 species of birds commonly seen in cropfarms, school buildings, fruit and flower trees. The nesting behavior of some of these birds on school buildings and trees is considered by some people as a nuisance, consequently they should be eliminated. However, the ecological role played by these birds on seed dispersal, pollination, and feeding on insects that could be dangerous to agricultural crops is considered paramount. This study discovered that the low human population presence significantly influenced the social activity of birds. But birds were observed flying off campus during a heavy human presence that would noise the environment. Unfortunately, the absence of human population in the campus witnessed a low population and activity state of birds. 


\section{REFERENCES}

[1] Bezzel T M (1985). Could temperature and water availability drive elevational species richness patterns A global case study for bat. Global Ecol Biogeogr 16:1-13

[2] Blair R B (2004). The effects of urban sprawl on birds at multiple levels of organization.

[3] Blair RB (2001). Creating a homogenous avifauna. In: Marzluff JM, Bowman R, Donnelly R (eds.), Avian ecology and conservation in an urbanising world. Boston, Kluwer. Pp. 461-488.

[4] Blair RB (1996). Land use and avian species diversity along an urban gradient. Ecological Applications 6: 506-519.

[5] Blus J M and Henny R K (2002). Plant traits and local extinctions in natural grasslands along urban-rural gradient. J Ecol 93: 1203-13.

[6] Blair RB, Launer AE (1997). Butterfly diversity and human land use: species assemblages along an urban gradient. Biological Conservation 80: 113-125.

[7] Chinchilla K S (2009). Ecology and Urban Planning. Biodivers Consev 8:119-31.

[8] Clergeau P, Croci S, Jokimaki J, Kaisanlahti-Jokimaki., Dinetti M (2006). Avifauna homogenisation by urbanisation: Analysis at different European Latitudes Biological Conservation 127: 336 - 344.

[9] Clergeau P Savard G and Mennechez G (1998). Bird abundance and diversity along an urban- rural gradient: a comparative study between two cities on different continents. Condor 100: 413-25.

[10] Chamberlain J T Patten M A and Fabborg J (2009). The effects of urban patterns on ecosystem function. Int Reg Sci Rev 28:168-92.

[11] Cincotta J M (2003). Urban effects on native avifauna. A review. Landscape Urban Plan 74: 46-69.

[12] Connor E F and McCoy E D (1979). The statistics and biology of the species-area relationship. Am Naturalist 113:791-833.

[13] Dhindhsa H S and Saini H K (1994). Food of the rose ringed Parakeet Psittacula krameri: a quantitative study. J Bombay Nat Hist Soc 91:96-103.

[14] Edgar M A Montgomerie R D and Waterhead (1994). Risks and rewards of nest defence of parent birds. Quart Rev Biol 63:167-87.

[15] Ekane N B, (2000), The Socio Economic Impact of Pronus Africana Management in the Mount Cameroon Region. Case study of the Bukwango Community. Presented as partial fulfilment of the degree of M Sc. From the department of Urban Planning and Environment, Royal Institute of Technology Stockholm

[16] Emlen J T (1974). An urban Bird community in Tucson, Arizona: derivation, structure, regulation. Condor 76: $184-97$.

[17] Fernandez-Juricic E (2000). Avifaunal use of wooded streets in an urban landscape. Conservation Biology 14: 513-521.

[18] Fitton, J.D., Kilburn, C.R.J., Thirwall, M.F., Hughes, D.J., (1983). 1982 eruption of Mt. Cameroon, West Africa. Nature 306, 327e332

[19] Germaine D S Morneau F Decarie R and Lambert D (1998). Changes in breeding bird riochness and abundance in monetral parks over a period of 15 years. Landsc Urban Plan 44: 111-21.

[20] Gilbert O (1989). Differential changes in bird community structure with urbanization: a study in central Finland. Ornis Scandinivia 9: 94-99.

[21] Hadiadian J K, Reynaud P A and Sandstorm W A (1997). Use of native and exotic garden plants by suburban nectarivorous birds. Biol Conserv Biol 2: 219-24

[22] Haslem A and Bennett A F (2008). Birds in agricultural mosaics: the influence of landscape

[23] pattern and countryside heterogeneity. Ecol Appl 18: 185-96.

[24] Herkert J R (1994). The effects of habitat fragmentation on Midwestern grassland communities. Ecol Appl 4 (3) : 461-71.

[25] Hmaer R K, Roswall K A and Witcher S M (2006). Robust behavioral effects of song in the absence of testosterone or corticosterone release in two songbird populations. Horm Behav 62: 418-25.

[26] Janssens M K, Mormul R P and Thomaz A M (2003). Structural complexity and distance from source habitat determine abundance and diversity. Biotropica 43:738-45.

[27] Johnson S (2000). Threshold responses of forest birds to landscape changes around exurban development. PLOS ONE 8e67593.

[28] Joikimaki T (1996). Avian response to landscape pattern: the role of species" life histories. Landscape Ecol 7: 163-80. 
[29] Lande R (1988). Genetics and demography in biological conservation. Science 241: 1455-1460.

[30] Landsberg HE (1981). The urban climate. International Geophysics Series 28: 275.

[31] MacArthur RH 1972 Geographical ecology. New York, Princeton University Press.

[32] Marzluff JM, Kern E (2001). Restoration of fragmented landscapes for the conservation of birds: A general framework and specific recommendations for urbanizing landscapes. Restoration Ecology 9: 280-292.

[33] McKinney ML (2002). Urbanization, biodiversity, and conservation. Bioscience 52: 883-890.

[34] Mills D C (1999). Living in city: resource availability, predation and bird population dynamics in urban areas. $J$ theor Biol 247:36-49

[35] Mills A J McCain C M and Palmer M (1989). Could temperature and water availability drive elevational species richness patterns? A global case study for bat. Global Ecol Biogeogr 8:13-20

[36] Parasharya M K (1994). Restoration of fragmented landscapes for the conservation of birds: general framework and specific framework and specific recommendations for urbanizing landscapes. Urban Ecol 9: 280-92.

[37] Rapoport EH 1993. The process of plant colonisation in small and large cities. In: M ecology of subtle human effects and populated areas. New York, Spriger-Verlag. cDonnell MJ, Pickett STA (eds.), Humans as components of ecosystems: the Pp. 190-207.

[38] Rebele F (1994). Urban ecology and special features of urban ecosystems. Global Ecology and Biogeography Letters 4: 173 -187.

[39] Richner K (1989). On bird species diversity Ecology 42:594-8.

[40] Saini H S Dhindhsa M K and Manjit S (1994). Significance of birds management and control.Pestology.10:74-73

[41] Schifferli L (2001). Birds breeding in changing farmland. Acta Ornithologica 36:37-51.

[42] Shannon CE, Weaver W (1963). The mathematical theory of communication. Illinois, University of Illinois.

[43] Tanjong, E. (2014). Socio-economic survey of the villages of Mount Cameroon National Park (MCNP).Program for Sustainable Management of Natural Resources Cameroon - South-West Region, Buea, Cameroon.

[44] Vitousek PM, Mooney HA, Lubchenco J, Melillo JM (1997). Human domination ecosystems. Science 277: 494-499.

[45] Warren P S, Katti M, Emran M and Brazel A (2006). Urban Bioacoustics: Its not just noise. Anim Behav 71:491-502.

[46] Whittaker K A Marzluff J M (2012). Post-fledging mobility in an urban landscape. In: Lepczyk C A and Warren P S (eds) Urban Bird Ecology and Conservation. Stud avain boil (no. 45). University of California press, Berkeley, CA, pp 183-93.

Citation: Melle Ekane Maurice, et.al, "The Impact of Human Presence on the Behavioral Activity of Birds in Buea University Campus, Southwest Region, Cameroon”, International Journal of Forestry and Horticulture, 6(3), pp. 1-11. DOI: https:// doi.org/10.20431/2454-9487.0603001

Copyright: (C) 2020 Authors, this is an open-access article distributed under the terms of the Creative Commons Attribution License, which permits unrestricted use, distribution, and reproduction in any medium, provided the original author and source are credited. 